\title{
Awareness and Implementation of Integrated Management of Childhood Illness (IMCI) Among Nurses in Paediatric Settings of Selected Hospitals in Ibadan, Nigeria.
}

\author{
Omobolanle Elizabeth Adekanye, $\mathrm{RN}^{1}$ and Titilayo Dorothy Odetola, \\ $\mathrm{RN}, \mathrm{BNSc}, \mathrm{MSc}^{2}$ \\ ${ }^{1}$ (Department of Nursing, University of Ibadan, Nigeria) \\ 2 (Department of Nursing, University of Ibadan, Nigeria)
}

\begin{abstract}
:
Background: The Integrated Management of Childhood Illness (IMCI) is a child health strategy developed by the World Health Organization and UNICEF aimed at reducing child morbidity and mortality. This study aimed to assess the level of awareness and implementation of IMCI among nurses in paediatric settings and to resensitize them about reduction of infant morbidity and mortality rates through IMCI implementation.

Methods: A random sampling technique was used for selecting 110 respondents and a self developed questionnaire was used to collect data. Hypotheses were tested using Pearson chi-square.

Results: It was deduced from the findings that nurses' years of experience in paediatric setting had little or no influence on their knowledge and practice of IMCI; that nurses' knowledge of IMCI affects their implementation and that IMCI implementation is influenced by institutional support, nurses attitude and parents or guardians compliance.

Conclusion: The IMCI strategy is effective in the reduction of under-five's morbidity and mortality if properly and efficiently implemented and supervised. Nevertheless, the implementation of the IMCI strategy is not optimal due to various factors that can otherwise be overcome by local/institutional interventions.
\end{abstract}

Keywords: Awareness, Implementation, Integrated management of childhood illnesses, Paediatric, Nurses

\subsection{Background of study}

\section{Introduction}

Since the 1970s, the estimated annual number of deaths among children less than 5 years old has decreased by almost a third. This reduction, however, has been very uneven and in some countries, rates of childhood mortality are increasing. In 1998, more than 50 countries still had childhood mortality rates of over 100 per 1000 live births [WHO, CAH 2007]. Every year, about 12 million children in developing countries die before they reach their fifth birthday, mostly during the first year of life. Seven in ten of these deaths are due to five main diseases: acute respiratory infections (mostly pneumonia), diarrhoea, measles, malnutrition, and malaria with illnesses are managed from when the child is one week old to five years old: diarrhoea, acute respiratory infections (including asthma), upper respiratory infections (including ear infections), malnutrition, tuberculosis, HIV/AIDS, child abuse, meningitis, management of the critically ill child [Western Cape Government 2005]. It was thus decided to focus on improving care at the first level health facilities where millions of children arrive sick each day, most of them with one or more of the major causes of illness and death.

Projections based on the 1996 analysis The global burden of disease indicate that these conditions will continue to be major contributors to child deaths in the year 2020 unless significantly greater efforts are made to control them. Every day, millions of parents take children with potentially fatal illnesses to first-level health facilities such as clinics, health centres and outpatient departments of hospitals. In some countries, three in four episodes of childhood illness are caused by one of these five conditions. And most sick children present with signs and symptoms related to more than one. This overlap means that a single diagnosis may not be possible or appropriate, and that treatment may be complicated by the need to combine therapy for several conditions. Surveys of the management of sick children at these facilities reveal that many are not properly assessed and treated and that their parents are poorly advised.

At this level, in most developing countries, diagnostic supports such as radiology and laboratory services are minimal or non-existent; and drugs and equipment are scarce. Limited supplies and equipment, combined with an irregular flow of patients, leave health care providers at first-level facilities with few opportunities to practise complicated clinical procedures. Instead, they must often rely on history and signs and symptoms to determine a course of management that makes the best use of available resources [WHO, CAH 2007]. 
Providing quality care to sick children in these conditions is a serious challenge. In response to this challenge, WHO and UNICEF developed a strategy known as Integrated Management of Childhood Illness (IMCI). Although the major stimulus for IMCI came from the needs of curative care, the strategy combines improved management of childhood illness with aspects of nutrition, immunisation, and other important disease prevention and health promotion elements. The objectives are to reduce deaths and the frequency and severity of illness and disability and to contribute to improved growth and development.

The strategy includes three main components:

- Improvements in the case-management skills of health staff through the provision of locally adapted guidelines on IMCI and through activities to promote their use.

- Improvements in the health system required for effective management of childhood illness.

- Improvements in family and community practices.

For IMCI to make an impact, the above three components must go together in tandem. This means that at least $60 \%$ of health workers who manage under-fives in $80 \%$ of our health facilities should be trained in IMCI case management. Trained health workers must also be supervised to reinforce their skills. The strategy focuses on the child as a whole, rather than on a single disease or condition. The child is treated holistically with evidence based interventions that are feasible to implement in countries where most child deaths occur [WikiEducator 2007].

There have been very few previous published researches on the level of awareness and implementation of IMCI in Nigeria despite its valuable impact. This article discusses the assessment of IMCI awareness and implementation levels in Nigeria. It also discusses factors that affect implementation of the IMCI strategy in Nigeria.

\subsection{Statement of the problem}

Every year 700,000 children die and most of them because of very common problems like measles, malnutrition, ARI, diarrhoea and other vaccine preventable diseases. For a number of reasons, health planners have not paid attention to the health needs of these children [Nisar 2003]. This research work will help explore some of these reasons. According to the study carried out by Chopra et al(2004), the findings has shown that under normal operating conditions and in a context of good facility infrastructure and management support, IMCI is associated with improvements in some important aspects of care [Chopra et al, 2004]. Every day, millions of parents seek health care for their children, taking them to hospitals, health centres, pharmacists, community health care providers and traditional healers. At least three out of four of these children are suffering from one of these five conditions [Nisar 2003].

Many of these preventable childhood illnesses are seen more in the communities. The primary healthcare clinics are predominantly nurse led with medical officers conducting occasional sessions. It is of great importance that health care practitioners be aware of the IMCI concept and programme and the implementation of the IMCI intervention for management of childhood illnesses. The purpose of this research study was to identify the level of awareness and implementation of IMCI interventions, identify factors affecting effective implementation of IMCI interventions among nurses working in paediatric units in Ibadan.

\subsection{Purpose of this research work}

There have been various research works on IMCI, which ranges from experiences of training, effects of implementation of the IMCI strategy to the assessment of the quality of care experienced with IMCI implementation. Diverse results and findings were gotten which have helped in improving health care services to under- five children.

The result and findings of this research work will serve as baseline information for future research studies. It will help in identification of the level of awareness and reported implementation of the IMCI strategy among nurses that are working in paediatric settings. It will also improve awareness on reduction of morbidity and mortality rates of under- five children through IMCI implementation. It will provide a means to measure the change in quality of care provided to sick children as a result of the routine implementation of the IMCI intervention.

The specific objectives of this research work include:

1. To assess the influence of nurses' years of experience in paediatric setting on their knowledge and practice of IMCI.

2. To explore the impact of nurses' knowledge on their practice of IMCI interventions.

3. To explore the attitude of nurses to the implementation of the IMCI strategy.

4. To identify the factors influencing effective implementation of the IMCI interventions. 


\subsection{Study setting and population}

\section{Methods}

This study was carried out at the paediatrics units of selected health facilities in Ibadan. The study population consisted of one hundred and ten nurses (110) working on paediatric wards/clinics.

\subsection{Data collection and analysis}

A descriptive survey design was used whereby questionnaires were administered to the respondents and retrieved after completion. A systematic random sampling technique was used for selecting 110 respondents and the instrument used was a self-designed and self-administered structured questionnaire.

The socio-demographic data from the respondents were summarized using frequency tables, percentages and charts, while other sections were analysed using statistical package for social sciences (SPSS).

\subsection{Consent and ethical approval}

An institutional ethical approval was sought and gained for the conduct of the study while verbal consent was taken with confidentiality assured to each respondent before administering the questionnaires.

\section{Results}

Table 3.1: Socio-demographic characteristics of the respondents.

\begin{tabular}{|l|l|l|}
\hline Variable & Frequency & Percentage \\
\hline Gender & & \\
Male & 0 & 0 \\
Female & 110 & 100 \\
\hline Age & & \\
$21-25$ & 5 & 4.5 \\
$26-30$ & 26 & 23.6 \\
$31-35$ & 22 & 20 \\
$36-40$ & 15 & 13.6 \\
$41-45$ & 21 & 19.1 \\
$46-50$ & 9 & 8.2 \\
$51-55$ & 8 & 7.3 \\
$56-60$ & 4 & 3.6 \\
Total & $\mathbf{1 1 0}$ & $\mathbf{1 0 0}$ \\
\hline Cadre & & \\
CNO & 13 & 11.8 \\
PNO & 24 & 21.8 \\
SNO & 24 & 21.8 \\
NOI & 28 & 25.5 \\
NOII & 21 & 19.1 \\
Total & $\mathbf{1 1 0}$ & $\mathbf{1 0 0}$ \\
\hline Professional Qualification & & \\
RN & 3 & 2.7 \\
RN/RM & 75 & 68.2 \\
RN/RM/RPH & 7 & 6.4 \\
RN/RP & 11 & 10.0 \\
RN/RM/BNSc & 14 & 12.7 \\
Total & $\mathbf{1 1 0}$ & \\
\hline Total Years of Experience & & \\
$0-5$ & 27 & 24.5 \\
6-10 & 27 & 24.5 \\
$11-15$ & 19 & 17.3 \\
$16-20$ & 12 & 10.9 \\
$21-25$ & 10 & 9.1 \\
$26-30$ & 8 & 7.3 \\
$31-35$ & 6 & 5.5 \\
$36-40$ & 1 & 0.9 \\
Total & $\mathbf{1 1 0}$ & $\mathbf{1 0 0}$ \\
\hline Years of Practice in Paediatrics & & \\
$0-10$ & 104 & 94.5 \\
$11-20$ & $\mathbf{1 1 0}$ & $\mathbf{1 0 0}$ \\
Total & & \\
\hline
\end{tabular}

TABLE 3.1 represents the socio-demographic characteristics of the nurses that participated in this study. Five cadres of nurses participated in this research study and the respondents were grouped under 5 professional qualification groups. Their total years of experience in nursing practice and their years of practice in paediatrics were measured and grouped as reported. 
Table 3.2: Nurses knowledge and awareness of the IMCI strategy

\begin{tabular}{|l|l|l|}
\hline Variables & $\begin{array}{l}\text { Yes } \\
\text { Frequency (\%) }\end{array}$ & $\begin{array}{l}\text { No } \\
\text { Frequency (\%) }\end{array}$ \\
\hline Awareness of IMCI & $73(66.4 \%)$ & $37(33.6 \%)$ \\
\hline Source of Information: & $31(28.2 \%)$ & \\
During Training & $28(25.5 \%)$ & \\
Clinical Practice & $6(6.4 \%)$ & \\
Conference/Seminar/Workshop & $1(0.5 \%)$ & \\
Internet & $19(27.3 \%)$ & $91(82.7 \%)$ \\
Books/Journal & & \\
\hline Any form of training about IMCI implementation & \\
& & \\
Impact of prompt and effective care on a patient's clinical & & \\
outcome & 0 & \\
Very Low & $3(2.7 \%)$ & \\
Low & $92(83.6 \%)$ & \\
Very High & $15(13.6 \%)$ & $(19.1 \%)$ \\
\hline Knowledge of IMCI components & $89(80.9 \%)$ & \\
\hline
\end{tabular}

TABLE 3.2 shows that all $73(66.4 \%)$ of the respondents were aware of the IMCI strategy and $37(33.6 \%)$ were not. $69(62.7 \%)$ of the respondents have high level of awareness while $41(37.3 \%)$ have low level of IMCI awareness.

Table 3.3: Nurses attitude towards the implementation of the IMCI strategy

\begin{tabular}{|c|c|c|}
\hline Variables & $\begin{array}{l}\text { Yes } \\
\text { Frequency }(\%)\end{array}$ & $\begin{array}{l}\text { No } \\
\text { Frequency }(\%)\end{array}$ \\
\hline $\begin{array}{l}\text { Effectiveness of the IMCI strategy in the reduction of } \\
\text { under } 5 \text { mortality rate } \\
\text { Very Low } \\
\text { Low } \\
\text { High } \\
\text { Very High }\end{array}$ & $\begin{array}{l}1(0.9) \\
5(4.5 \%) \\
83(75.5 \%) \\
21(19.1 \%)\end{array}$ & \\
\hline $\begin{array}{l}\text { Previously used case management is better and more effective } \\
\text { than IMCI guidelines }\end{array}$ & $50(45.5 \%)$ & $60(54.5 \%)$ \\
\hline $\begin{array}{l}\text { IMCI guidelines is an underutilization of clinical training } \\
\text { among health care professionals }\end{array}$ & $19(27.3 \%)$ & $91(82.7 \%)$ \\
\hline $\begin{array}{l}\text { Impact of IMCI strategies on skill improvement in child } \\
\text { management }\end{array}$ & $80(72.7 \%)$ & $30(27.3 \%)$ \\
\hline IMCI guidelines require adequate time for implementation & $107(97.3 \%)$ & $3(2.7 \%)$ \\
\hline Attendance of any conference/seminar/workshop & $9(8.2 \%)$ & $101(91.8 \%)$ \\
\hline Lack of compliance by parents/guardians & $108(98.2 \%)$ & $2(1.8 \%)$ \\
\hline $\begin{array}{l}\text { Frequency of health education to parents/guardians on } \\
\text { compliance by nurses } \\
\text { Rarely } \\
\text { Seldom } \\
\text { Often } \\
\text { Regularly } \\
\text { Routinely }\end{array}$ & $\begin{array}{l}4(3.6 \%) \\
30(27.3 \%) \\
65(59.1 \%) \\
8(7.3 \%) \\
3(2.7 \%)\end{array}$ & \\
\hline
\end{tabular}

TABLE 3.3 represents the variables used to determine the attitude of nurses towards the implementation of the IMCI strategy. $56(50.9 \%)$ of the respondents had a high positive attitude towards the IMCI strategy.

Table 3.4: Factors influencing IMCI implementation

\begin{tabular}{|l|l|l|}
\hline Variables & $\begin{array}{l}\text { Yes } \\
\text { Frequency(\%) }\end{array}$ & No Frequency(\%) \\
\hline $\begin{array}{l}\text { Importance of the IMCI strategy implementation, } \\
\text { among all client's issues at health care institutions: }\end{array}$ & & \\
& 88 & 80.0 \\
Low Priority & 18 & 16.4 \\
Moderate Priority & 4 & 3.6 \\
$\begin{array}{l}\text { High Priority } \\
\text { Very High Priority }\end{array}$ & 0 \\
\hline $\begin{array}{l}\text { Has the institution organised or sent nurses for any } \\
\text { seminar/workshop? }\end{array}$ & $10(9.1 \%)$ & $100(90.9 \%)$ \\
\hline $\begin{array}{l}\text { Has the institution taken any steps to encourage } \\
\text { community participation in IMCI }\end{array}$ & $19(27.3 \%)$ & $91(82.7 \%)$ \\
\hline $\begin{array}{l}\text { Unavailability of enough professional tools like wall } \\
\text { charts and chart booklets for proper IMCI } \\
\text { implementation }\end{array}$ & $108(98.2 \%)$ & $2(1.8 \%)$ \\
\hline
\end{tabular}




\begin{tabular}{|l|l|l|}
\hline $\begin{array}{l}\text { Improvisation of materials when taking care of a sick } \\
\text { child }\end{array}$ & $107(97.3 \%)$ & $3(97.3 \%)$ \\
\hline $\begin{array}{l}\text { Level of supervision on IMCI implementation in the } \\
\text { paediatric units under study }\end{array}$ & & \\
Rarely & $38(34.5 \%)$ & \\
Seldom & $55(50.0 \%)$ & \\
Often & $13(11.8 \%)$ & \\
Regularly & $3(2.7 \%)$ & \\
Routinely & $1(0.9 \%)$ & \\
\hline Availability of emergency drugs according to the & & \\
IMCI recommended list in the paediatric units & & \\
under study & $1(0.9 \%)$ & \\
Always & $4(3.6 \%)$ & \\
Often & $73(66.4 \%)$ & \\
Sometimes & $30(27.3 \%)$ & $2(1.8 \%)$ \\
Seldom & $2(1.8 \%)$ & \\
Never & $108(98.2 \%)$ & \\
\hline Need for more nursing staffs on the wards/clinic to & \\
allow for proper IMCI implementation & & \\
\hline
\end{tabular}

TABLE 3.4 describes the variables used explore various factors perceived to influence the implementation of IMCI at selected paediatric settings in Ibadan.

\section{Discussions}

It was deduced from the findings that though nurses working in the paediatric units are still in active professional phases and should be capable of implementing IMCI, only a very few have undergone the required paediatric nursing training. It was discovered that unit rotation was frequently done in the various hospitals which prevented nurses from spending many years in the paediatric unit. This serves as a limitation to gaining proficiency in paediatric management as there is no sufficient time to practice and gain expertise. It was also found out that nurses' knowledge of IMCI greatly influence their implementation of IMCI interventions. Majority of the nurses gained knowledge and became aware of the IMCI strategy during their training and in clinical practice. Majority of the nurses didn't see any reason to undergo a personal IMCI training since their organization didn't send them for it. They also couldn't get time off work for personal IMCI training especially with the problem of understaffing.

More than $50 \%$ of the respondents had fair knowledge and implementation of IMCI but completion and proper use of the guidelines was limited. Majority of the nurses believed that the IMCI strategy is very effective in the reduction of under-five mortality. Majority of the nurses had the belief that implementing the IMCI guidelines would have a positive effect on their skill in paediatric management and bring about an improvement in the management of their clients. It was a general claim that the IMCI guidelines required adequate time for implementation and as such would increase the average time for assessing, managing/ treating children. The nurses found it difficult implementing the IMCI guidelines because it required too much time and they also didn't attend any training to learn about IMCI.

IMCI implementation is affected by inadequate professional aids like wall charts and chart booklets for proper IMCI implementation and nurses have had to improvise materials when taking care of a sick child. Majority of the respondents claimed that supervision of IMCI implementation by the institutions was rare and inconsistent. This made maintenance and sustenance of the IMCI strategy difficult. The emergency drugs according to the IMCI recommended list were not usually available in the paediatric unit which made case management difficult and ineffective.

There was a need for improved staffing on paediatric wards/clinics to allow for proper IMCI implementation. The IMCI guidelines required adequate time for proper assessment, treatment and caretaker counselling to take place and has such would increase the average time for assessing and treating children. This research work found out that IMCI implementation is affected and influenced by institutional support, nurses attitude and parents or guardians compliance.

\section{Conclusion}

WHO and UNICEF developed the IMCI strategy to reduce child morbidity and mortality and to enhance child growth and development in middle and low income countries in 1996 [Steer et al, 2009]. There have been various research works on IMCI, which ranges from experiences of training, effects of implementation of the IMCI strategy to the assessment of the quality of care experienced with IMCI implementation. Diverse results and findings were gotten which have helped in improving health care services to under- five children. 
The result and findings of this research work will serve as baseline information for future research studies. It will help in identification of the extent of awareness and level of the IMCI strategy among nurses that are working in paediatric settings. It also will create awareness on reduction of morbidity and mortality rates of under- five children through IMCI implementation. It will provide a means to measure the change in quality of care provided to sick children as a result of the routine implementation of the IMCI intervention. My study on IMCI will enable the existing body of knowledge identify the extent of the IMCI strategy awareness and level of implementation.

It was deduced from the findings that the nurses working in the paediatric unit are still in active phases and can perform active implementation of IMCI, but only a very few of the nurses have undergone paediatric nursing training. Nurses need to be encouraged and motivated to specialize to improve their efficiency. Nurses working in paediatric areas need to undergo training on the IMCI strategy to improve their skills in caring for under- five's and keep them abreast of new innovations, strategies and technology involving management of children. This will also ensure an evidence-based nursing practice.

Majority of the nurses had the belief that implementing the IMCI guidelines would have a positive effect on their skill in paediatric management and bring about an improvement and will ensure a good use of their clinical training. IMCI implementation was found to be influenced by institutional support, nurses attitude and parents or guardians compliance. Nurse managers need to advocate for nurse clinicians in health organizations so that proper training, implementation and supervision of the IMCI strategy can be ensured and maintained to ensure a significant improvement in child's health thereby achieving the $4^{\text {th }}$ Millennium Development Goal (MDG).

\section{References}

[1]. World Health Organization Child and Adolescent Health and Development (CAH). (2007). WHO/UNICEF strategy of Integrated Management of Childhood Illness (IMCI). Retrieved May 8, 2012, from http://www.who.int/child_adolescent_health/en/

[2]. Western Cape Government. (2005). Integrated Management of Childhood Illnesses (IMCI). Retrieved May 8, 2012, from www.westerncape.gov.za/eng/directories/services/.../6415

[3]. WikiEducator. (2007). Lesson 2: Integrated Management of Childhood Illness (IMCI). Retrieved June 4, 2012, from http://wikieducator.org/IMCI/

[4]. Nisar, N. (2003). Integrated Management of Childhood illness and Health System Reforms In Pakistan. Karachi, Rawal Medical Journal 2003; 28:44-47

[5]. Chopra, M., Patel, S., Cloete, K., Sanders, D., \& Peterson, S. (2004). Effect of an IMCI intervention on quality of care across four districts in Cape Town, South Africa. Archives of Disease in Childhood 2005;90:397-401 doi:10.1136/adc.2004.059147

[6]. Steer, A.C., Tikoduadua, L.V., Manalac, E.M., Colquhoun, S., Carapetis, J.R. \& Maclennan, C. (2009). Validation of an Integrated Management of Childhood Illness algorithm for managing common skin conditions in Fiji. Bulletin of the World Health Organization 2009;87:173-179. doi: 10.2471/BLT.08.052712.v 